\title{
Total phenolic, antioxidant activity and physic-chemical properties of waxy pigmented and non-pigmented rice in Cambodia
}

\author{
${ }^{1,3 *}$ Chay, C., ${ }^{2}$ Hurtada, W.A., ${ }^{3}$ Dizon, E.I., ${ }^{4}$ Elegado, F.B., ${ }^{1}$ Norng, C. and \\ ${ }^{2}$ Raymundo, L.C. \\ ${ }^{1}$ Royal University of Agriculture, Phnom Penh, Cambodia \\ ${ }^{2}$ Institute of Human Nutrition and Food, College of Human Ecology, University of the Philippines \\ Los Baños, College, Laguna - 4031, Philippines \\ ${ }^{3}$ Institute of Food Science and Technology, College of Agriculture, University of the Philippines \\ Los Baños, College, Laguna-4031, Philippines \\ ${ }^{4}$ The National Institute of Molecular Biology and Biotechnology (BIOTECH), University of the \\ Philippines Los Baños, College, Laguna - 4031, Philippines
}

\begin{abstract}
Article history:
Received : 9 January 2017 Received in revised form : 14 January 2017 Accepted : 15 January 2017 Available online : 18 January 2017
\end{abstract}

Keywords:

Waxy pigmented and nonpigmented rice,

Proximate properties

Total phenolic content

Antioxidant activity

\section{DOI}

http://doi.org/10.26656 fr.2017.1.002

\section{Introduction}

In the mid-1990s food security was recognized as a significant concern, spanning a spectrum from the individual to the global level. However, access now involved sufficient food, indicating continuing concern with protein-energy malnutrition. But the definition was broadened to incorporate food safety and also nutritional balance, reflecting concerns about food composition and minor nutrient requirements for an active and healthy life. At present, food security does not only mean enough quantity of food to feed the population but exists when all people, at all times, have physical, social and economic access to sufficient, safe and nutritious food which meets their dietary needs and food preferences for an active and healthy life.

Domneub is a sweet rice or glutinous rice variety in Cambodia which has two types; the white waxy non-pigmented rice (Domneubsor in Khmer) and black waxy pigmented rice (Domneobkhmau in Khmer). Domneubsor is used throughout the country for production of rice cake, dessert, tape (saccharified rice), among others, while the Domneubkhmau is used for traditional medicine processing by fermentation, fish fermentation, tapekhmau (black saccharified rice). However, there is very limited information about the benefits and composition properties in both rice.

Pigmented or colored rice is characterized by its grain with red brown or dark purple color covering layers. Pigments, which are located in the aleurone layer of rice grain, have been reported as a mixture of anthocyanin compounds, which belong to the family of flavonoids (Yawadio et al., 2007). The phenolic compounds have been found as a major active component for antioxidation (Iqbal et al., 2000; Zhang et al., 2006; Yawadio et al., 2007; Tabart et al., 2009). Antioxidative activity of pigmented rice has been reported by Zhang et al. (2006); Nam et al. (2006) and Chung and Shin (2007). However, there is no specific information on the total phenolic content and the antioxidant activity of Domneubsor and Domneubkhmau grown in Cambodia. 
Thus, this study evaluated the physicochemical properties, total phenolic content and antioxidant activity of the waxy pigmented and non-pigmented Cambodian rice varieties.

\section{Materials and methods}

\subsection{Materials}

Waxy pigmented and non-pigmented rice varieties were purchased from Cambodia and transported to the Philippines for properties composition analysis. Waxy pigmented rice was obtained from Trapeang Ta Moung Village, Prey SleokCommune, Treang District, Takeo Province known as angkordomneubkhmao or black sticky rice. The waxy non-pigmented rice was collected from Teamchas Village, Kompongsvay Commune and District, Kompong Thom Province, Cambodia locally known as angkordomneubsor or white sticky rice.

\subsection{Amylose content (AC)}

The amylose content of the rice samples was determined by Iodine-Amylose colorimetric assays for apparent AC method following the procedure of Juliano et al. (2012). Waxy pigmented and nonpigmented milled rice flour $(100 \mathrm{mg})$ were wetted with $1.0 \mathrm{~mL}$ of $95 \%$ ethanol and swirled carefully to disperse clumps. The ethanol-wetted flour was dispersed in $1 \mathrm{~N} \mathrm{NaOH}(9.0 \mathrm{~mL})$ in a $100 \mathrm{~mL}$ volumetric flask and allowed to stand overnight. The mixture was made up to $100 \mathrm{~mL}$ with distilled water, mixed and a $5 \mathrm{~mL}$ aliquot $(0.09 \mathrm{~N} \mathrm{NaOH})$ was placed in a $100 \mathrm{~mL}$ volumetric flask with $\approx 50 \mathrm{~mL}$ of distilled water. Then, $1.0 \mathrm{~mL}$ of $0.9 \mathrm{~N} \mathrm{NH} 4 \mathrm{Cl}$ was added, followed by $2 \mathrm{~mL}$ of $0.15 \%$ iodine in $1.5 \% \mathrm{KI}$, and the solution was made up to volume with distilled water to obtain a stable deep-blue color with the least amount of interference from amylopectin (waxy starch produces a greenish tinge). The absorbance of the color was read at $620 \mathrm{~nm}$ within 20-60 minutes and its stability and $\mathrm{pH}$ were measured. $\mathrm{AC}$ was calculated from standard curves based on potato amylose $\mathrm{V}$ (Avebe) alone (0, 5, 10, 15, 25 and 35 $\mathrm{mg} / 100 \mathrm{~mL}$ ) of $0.09 \mathrm{~N} \mathrm{NaOH}$.

Rice varieties were classified into five groups according to their amylose content: waxy $(0.0-2 \%)$, Very low amylose (2.1-9.9\%), low amylose (10.0$17.0 \%)$, intermediate amylose (17.1-21.9\%) and high amylose ( $\geq 22.1 \%)$ (Rice Chemistry and Quality Laboratory, Philippine Rice Research Institute, University of the Philippines Los Banos 2014).

\subsection{Physicochemical analysis}

The physicochemical properties of both the raw materials (waxy pigmented and non-pigmented rice) inrice wine resulting from traditional and multiparallel fermentation using the developed starter culture were analyzed. For the raw materials, one hundred grains of each rice variety were taken randomly and the length and width were measured by using a micrometer. Representative samples of waxy pigmented and non-pigmented rice varieties $(50 \mathrm{~g})$ were drawn randomly and thousand grain weights was recorded in grams/1000 kernel by counting grains and weighing on an electric balance described by AACC (2000). Protein content was determined using a Kjeldahl digestion system based on the Association of Official Analytical Chemists (AOAC) method (2000). Crude fat was determined by extraction with hexane for $6 \mathrm{~h}$ using a Soxhlet apparatus. Ash content was determined by burning in a muffle furnace at $550^{\circ} \mathrm{C}$ for $3 \mathrm{~h}$ according to the AACC (2000). The moisture content in each sample was determined by drying $4 \mathrm{~g}$ sample in an air forced draft oven maintained at a temperature of $105 \pm 5^{\circ} \mathrm{C}$ according to the procedure described in AACC (2000) method No. 44-15A. For the determination of fiber content, the rice samples were digested with $1.25 \% \mathrm{H}_{2} \mathrm{SO}_{4}$ followed by $1.25 \% \mathrm{NaOH}$ solution and crude fiber content was determined according to AACC (2000) method No. 32-10.

\subsection{Determination of total phenolic content}

The total phenolic content was determined by Folin-Ciocalteu method according to the procedure of Teresa Escribano-Bailón et al. (2002). The sample was diluted with water and to $0.5 \mathrm{~mL}$ of the diluted samples, $0.5 \mathrm{~mL}$ of Folin-Ciocalteu's phenol reagent (Sigma-Aldrich) and $0.5 \% \mathrm{Na} 2 \mathrm{CO} 3$ were added. After standing for 5 minutes, $5 \mathrm{~mL}$ distilled water were added. The absorbance readings were measured at $720 \mathrm{~nm}$ (Shimadzu UV-1601 spectrophotometer) with water plus reagent as blank sample. Total phenolic content was computed in a standard curve with gallic acid as reference phenol. The results were expressed as gallic acid equivalents $\left(\mathrm{GAE} \mathrm{mL}^{-1}\right)$.

\subsection{Determination of antioxidant activity (DPPH radical scavenging method)}

Theantioxidantactivityofpolyphenolsismeasured in terms of hydrogen donating or radical scavenging ability using the stable radical 2,2-diphenyl-1picrylhydrazyl (DPPH) according to the method of Ribeiro et al. (2008) with some modifications with synthetic antioxidants butylatedhydroxy-anisole (BHA) and butylatedhydroxy-toluene (BHT) as reference antioxidants.

Five (5) $\mathrm{mL}$ of $0.1 \mathrm{mM} \mathrm{DPPH}$ were pipetted in 
test tubes and added with $100 \mu \mathrm{L}$ of the standards and sample. The mixture was vortexed and allowed to stand for 20 minutes. The control consisted of $100 \mu \mathrm{L}$ methanol and the reagent served as control. The absorbance was read at $517 \mathrm{~nm}$ with water to zero the instrument. The percentage of inhibition was expressed using the following equation:

$$
\% \text { Inhibition }=\left[\frac{A_{\text {control }}-A_{\text {Sample }}}{A_{\text {Control }}}\right] \times 100
$$

\subsection{Copper reduction antioxidant capacity (CUPRAC) test}

Copperreductionantioxidant capacity(CUPRAC) test is a variant of FRAP test using $\mathrm{Cu}$ instead of Fe. The assay is based on the reduction of $\mathrm{Cu}^{+2}$ to $\mathrm{Cu}^{+1}$ by the combined action of all antioxidants (reducing agents) in a sample. The $\mathrm{Cu}^{+1}$ then forms a yellow colored complex with neocuproine (2,9-dimethyl1,10-phenanthroline) which absorbs at $450 \mathrm{~nm}$. Therefore, the higher the absorbance at $450 \mathrm{~nm}$, the higher the reduction of copper by the antioxidants, the higher the antioxidant capacity, the better the health beneficial quality of foods. One (1) $\mathrm{mL}$ of $\mathrm{CuCl}_{2}, 1.0 \mathrm{~mL}$ of $\mathrm{NH}_{4} \mathrm{AC}, 1.0 \mathrm{~mL}$ of neocuproine, 0.5 $\mathrm{mL}$ of antioxidant and $0.6 \mathrm{~mL}$ of water were pipetted in test tubes. The concentration of antioxidants was prepared using different concentrations of $5,10,15$, 20 and $25 \mu \mathrm{g} \mathrm{GAEml}^{-1}$. The mixture was vortexed and allowed to stand for 30 minutes and then read at 450 against a blank sample consisted of water and the reagents (Alpinar et al., 2009).

\section{Results and discussion}

\subsection{Physicochemical properties of the waxy pigmented and non-pigmented rice}

Short-grained varieties of rice are considered best for sake (Japanese wine) manufacture and longgrained varieties are considered desirable. Types of rice-long grain, medium grain and short grain are based on the length: width ratio of kernels of rice grains that are unbroken (Matz, 1991). Table 1 shows the comparison of the physical and chemical properties between the rice varieties (Domneupkmau and Domneupsor) used in the study for production of rice wine. Both varieties fall under long-grained types. Their length ranges from 6 to $7 \mathrm{~mm}$ while the width is from 1.5 to $1.8 \mathrm{~mm}$.

The amylose content of rice is one of the most important criteria of rice quality in terms of cooking and pasting properties (Adu-Kwarteng et al., 2003). The rice varieties tested were observed, of which nonpigmented rice can be classified as the variety with "very low amylose" content than waxy pigmented rice. According to the classification of Rice Chemistry and Quality Laboratory, Philippine Rice Research Institute, University of the Philippines Los Banos, waxy rice (0.02-2.0\%) with very low amylose content (2.1-9.9\%) are sticky after cooking. Thus, waxy pigmented and non-pigmented rice samples are classified as varieties with "very low amylose" content and "waxy". In addition, amylopectin predominates in waxy rice whereas amylose is much more predominant in non-waxy rice. Amylose is more soluble in water than amylopectin and their ratio influences cooked rice properties.

Waxy non-pigmented rice has high moisture content (12.64\%) compared to waxy pigmented rice (11.7\%). In general, except for starch and moisture content, all mean values were found higher in waxy pigmented than non-pigmented rice variety. Protein influences the nutritional quality of rice. In this study the protein content was appreciably high (6-8\%) for both tested varieties. According to Nunokawa (1972), most rice varieties for sake making contain 7.0 to $9.0 \%$ crude protein.

Table 1. Physical and chemical properties of the waxy pigmented and non-pigmented rice.

\begin{tabular}{lcc}
\hline \multirow{2}{*}{ Constituents } & \multicolumn{2}{c}{ Waxy } \\
\cline { 2 - 3 } & $\begin{array}{c}\text { Pigmented } \\
\text { rice }\end{array}$ & $\begin{array}{c}\text { Non- } \\
\text { pigmented rice }\end{array}$ \\
\hline Starch (\%) & 86.69 & 92.66 \\
Amylose (\%) & 2.1 & 0.4 \\
Crude protein (\%) & 8.31 & 6.05 \\
Crude fat (\%) & 2.67 & 0.64 \\
Crude fiber (\%) & 0.77 & 0.15 \\
Crude ash (\%) & 0.59 & 0.46 \\
Moisture content $(\%)$ & 11.70 & 12.64 \\
Length (mm) & 7 & 6 \\
Width (mm) & 1.8 & 1.5 \\
Weight/1000grain & 16.57 & 14.54 \\
Rice type & Long-grain & Long-grain \\
Total phenolic content $\left(\mu \mathrm{g} \mathrm{g}^{-1}\right)$ & 2074 & 134 \\
\hline
\end{tabular}

\subsection{Total phenolic content in waxy pigmented and non-pigmented rice}

The total phenolic content of the waxy pigmented and non-pigmented rice samples expressed in milligram of gallic acid equivalent (GAE $100^{-\mathrm{g}}$ ) dry sample is presented in Table 1. The total polyphenol content of the different types of waxy rice varies significantly from each other. Results revealed that the waxy pigmented rice exhibited a significantly higher total polyphenol content of $2074 \mu \mathrm{g}$ GAE $\mathrm{g}^{-1}$ compared to that of the waxy non-pigmented rice of $134 \mu \mathrm{g} \mathrm{GAE} \mathrm{g}^{-1} \mathrm{db}$. Waxy pigmented rice 
had higher total phenolic content than waxy nonpigmented rice. The waxy pigmented rice had higher phenolic content than the red and black rice varieties with mean phenolic contents of 470.1 and 1055.7 $\mathrm{mg} / 100 \mathrm{~g}$, respectively, as reported by Goffman and Bergman (2004) and Shen et al. (2009). Polyphenols are the most effective antioxidative constituents in plant products consumed (Escribano-BailÓn et al., 2004).

\subsection{Antioxidant activity in waxy pigmented and non-pigmented rice}

DPPH radical scavenging activity. DPPH is a free radical that accepts an electron or hydrogen radical to form a more stable compound. DPPH assay is based on the decrease in purple color of the DPPH solution when the nitrogen atom in DPPH is reduced upon receiving a hydrogen atom from an antioxidant. The DPPH free radical scavenging effect expressed as percent inhibition of waxy pigmented and non-pigmented rice at various concentrations are shown in Table 2. The percentage of inhibition of the DPPH radical by the extracts of the waxy pigmented rice was observed to increase with increasing concentration which exhibited the highest percentage inhibition of $75.37 \%$. However, the percentage of inhibition of the DPPH radical by the extracts of the waxy non-pigmented rice decreased with increasing concentration which is $6.72 \%$ in total phenolic concentration of $1.7 \mu \mathrm{g} \mathrm{GAE} \mathrm{g}^{-1}$.

Table 2. DPPH radical scavenging activity in waxy pigmented and non-pigmented rice.

\begin{tabular}{ccc}
\hline \multirow{2}{*}{$\begin{array}{c}\text { Total phenolic } \\
\text { concentration }(\mu \mathrm{g} \\
\text { GAE g-1 }^{-1}\end{array}$} & \multicolumn{2}{c}{ DPPH inhibition (\%) } \\
\cline { 2 - 3 } & Pigmented Rice & $\begin{array}{c}\text { Non-pigmented } \\
\text { Rice }\end{array}$ \\
\hline 1.7 & 12.54 & 6.72 \\
5 & 22.99 & $\mathrm{Nd}$ \\
10 & 39.02 & $\mathrm{Nd}$ \\
20 & 52.09 & $\mathrm{Nd}$ \\
25 & 65.16 & $\mathrm{Nd}$ \\
\hline
\end{tabular}

\subsection{Copper reducing activity}

Copperreductionantioxidant capacity(CUPRAC) test is a variant of FRAP test using $\mathrm{Cu}$ instead of $\mathrm{Fe}$. The assay is based on the reduction of $\mathrm{Cu}^{+2}$ to $\mathrm{Cu}^{+1}$ by the combined action of all antioxidants (reducing agents) in a sample. The $\mathrm{Cu}^{+1}$ then forms a yellow colored complex with neocuproine (2,9-dimethyl1,10-phenanthroline) which absorbs at $450 \mathrm{~nm}$. Therefore, the higher the absorbance at $450 \mathrm{~nm}$, the higher the reduction of copper by the antioxidants; the higher the antioxidant capacity, the better the health beneficial quality of foods.

Copper, free and in phenanthroline complexes, has a lower redox potential than iron, so its reactions are more selective; sugars and citric acid, common interference with Ferric Reducing Ability of Plasma (FARP), are not oxidized in CUPRAC. At the same time, the low redox potential enhances redox cycling, so copper reduction may be an even more sensitive indicator of potential pro-oxidant antioxidants. In the present study, the percentage of copper reducing activity of the waxy pigmented and non-pigmented rice extracts was observed to increase with increasing concentration of the total phenolic concentration $\left(\mu \mathrm{g}\right.$ GAE $\left.\mathrm{g}^{-1}\right)$ the highest percentage of $0.754 \%$ and $0.377 \%$, respectively (Table 3 ). However, the percentage of copper reducing activity was already not detected in the extracts of the waxy nonpigmented rice at concentration of $20 \mu \mathrm{g} \mathrm{GAE} \mathrm{mg}^{-1}$.

Consumption of waxy pigmented rice resulted in reduced atherosclerotic lesions (Ling et al., 2001), reduced oxidative stress and inflammatory effects (Xia et al., 2003). Antioxidant activity in white rice hull had already been reported by Lee et al. (2003). Pigmented rice is composed of high content of phenolic compounds (Clifford, 2000; Oki et al., 2002). They are distributed in the plant as secondary structure metabolite (Matinez-Valverde et al., 2000). Various benefits of the phenolic compounds are known to have various effects in human including oxidative damage of lipid, low density lipoproteins inhibiting platelet aggregation (Daniel et al., 1999), and reduced coronary heart disease and cancer risk (Matinez-Valverde et al., 2000). Fruits and vegetables are major dietary sources of phenolic compounds (Tian et al., 2004), however, waxy pigmented and non-pigmented rice have been found as an excellent source of the phenolic compounds.

Table 3. The copper reducing activity of waxy pigmented and non-pigmented rice.

\begin{tabular}{|c|c|c|}
\hline \multirow{2}{*}{$\begin{array}{c}\text { Total phenolic } \\
\text { concentration }(\mu \mathrm{g} \\
\left.\text { GAEmg }^{-1}\right)\end{array}$} & \multicolumn{2}{|c|}{ Copper reducing activity (Absorbance) } \\
\hline & $\begin{array}{l}\text { Waxy Pigmented } \\
\text { Rice }\end{array}$ & $\begin{array}{c}\text { Waxy Non- } \\
\text { pigmented Rice }\end{array}$ \\
\hline 5 & 0.138 & 0.081 \\
\hline 10 & 0.310 & 0.191 \\
\hline 15 & 0.446 & 0.308 \\
\hline 20 & 0.613 & 0.377 \\
\hline 25 & 0.754 & $\mathrm{Nd}$ \\
\hline
\end{tabular}

*Higher values indicate higher copper reducing activity 


\section{Conclusion}

Waxy pigmented rice has $2.1 \%$ for amylose, $8.31 \%$ for crude protein, $2.67 \%$ crude fat, $0.77 \%$ crude fiber, $0.59 \%$ crude ash, $7 \mathrm{~mm}$ for length, 1.8 $\mathrm{mm}$ for width, $16.57 \mathrm{~g}$ weight/1000 grain, $2047 \mu \mathrm{g}$ $\mathrm{g}^{-1}$ for total phenolic content, $12.54 \%$ for DPPH and $0.138 \%$ CUPRAC compared to waxy non-pigmented rice but the $86.69 \%$ of starch and $11.7 \%$ of moisture content was lower compared to waxy non-pigmented rice. So, the waxy pigmented rice has higher TP, DPPH and CUPRAC then waxy pigmented rice.

\section{Acknowledgments}

The authors extend their gratitude and appreciation to the Southeast Asian Regional Center for Graduate Study and Research in Agriculture (SEARCA), Philippines for the scholarship grant; to the Royal University of Agriculture (RUA), for providing the opportunity and valuable assistance for the completion of the study; Food Science and Technology, and BIOTECH (UP Los Baños) laboratories, Philippines for assistance to determine thetotal phenolic content and antioxidant activity in materials and to the Rice Chemical and Quality Laboratory, Philippine Rice Research Institute Los Baños for assistance in determining amylose content.

\section{References}

American Association of Cereal Chemists (AACC). (2000). Approved Methods of the American Association of Cereal Chemists, 10th ed. St. Paul, MN: American Association of Cereal Chemists, Inc.

Association of Official Analytical Chemists (AOAC). (2000). Official Methods of Analysis. 17th ed. Washington, D.C.:Association of Analytical Chemists, Inc.

Alpinar, K., Ozyurek, M., Kolak, U., Guclu, K., Aras, M., Altun. C., Celik, S.E., Berker, K.I., Bektasoglu, B. and Apak, R. (2009). Antioxidant capacities of some food plants wildly grown in Ayvalik of Turkey. Food Science and Technology Research, 15(1), 59-64.

Chung, H.S. and Shin J.C. (2007). Characterization of antioxidant alkaloids and phenolic acids from anthocyanin-pigmented rice (Oryza sativa cv. Heugjinjubyeo). Food Chemistry, 104(4), 1670-1677.

Clifford, M.N. (2000). Anthocyanins: Nature, occurrence and dietary burden. Journal of Agricultural and Food Chemistry, 80, 1063-1072.

Daniel, O., Meier, M.S., Schlatter, J. and Frischkneecht, P. (1999-. Selected phenolic compounds in cultivated plants: Ecologic functions, health implications and modulation by pesticides. Environmental Health Perspectives, 107, 109-114.

Teresa Escribano-Bailón M., Celestino S-B. and RivasGonzalo J.C. (2004). Anthocyanins in cereals. Journal of Chromatography A, 1054(1-2), 129-141.

Goffman, F.D. and Bergman, C.J. (2004). Rice kernel phenolic content and its relationship with antiradical efficiency. Journal of the Science of Food and Agriculture, 84(10), 1235-1240.

Iqbal, S., Bhanger M.I. and Anwar, F. (2000). Antioxidant properties and components of some commercially available varieties of rice bran in Pakistan. Food Chemistry, 93(2), 265-272.

Juliano, B.O., Tuano, A.P.P., Monteroso, D.N., Aoki, N., Mestres, C., Duldulao, J.B.A. and Bergonio, K.B. (2012). Replacement of acetate with ammonium buffer to determine apparent amylose content of milled rice. Cereal Foods World, 57(1), 14-19.

Lee, S.C., Kim, J.H., Jeong, S.M., Kim, D.R., Ha, J.U., Nam, K.C. and Ahn, D.U. (2003). Effect of farinfrared radiation on the antioxidant activity of rice hulls. Journal Agriculture Food Chemistry, 51, 44004403.

Ling, W.H., Cheng, Q.X., Ma, J. and Wang, T. (2001). Red and black rice decrease atherosclerotic plaque formation and increase antioxidant status in rabbits. Journal Nutrition, 131, 1421-1426.

Matinez-Valverde I., Periago, M.J. and Ros, G. (2000). Nutritional importance of phenolic compounds in the diet. Arch Latinoam Nutrition, 50, 5-18.

Matz, S. (1991). The Chemistry and Technology of Cereals as Foods and Feeds 2nd ed., p. 516. Reinhold/Avenu Now York: Van Rostrand

Nam, S.H., Choi, S.P., Kang, M.Y., Koh, H.J., Kozukue, N. and Friedman, M. (2006). Antioxidative activities of bran extracts from twenty-one pigmented rice cultivars. Food Chemistry, 94(4), 613-620.

Ñunez Selles, A., Castro, H.T.V., Aguero, J.A., Gonzalez, J.G., Naddeo, F. Simone, F. and Rastrelli, L. (2002). Isolation and quantitative analysis of phenolic antioxidants, free sugars and polyols from mango (Mangiferaindica L.) stem bark aqueous decoction used in Cuba as a nutritional supplement. Journal of Agricultural Food Chemistry, 50, 762-766.

Nunokawa, Y. (1972). Sake. In Houston D. F. (Ed.). Rice: Chemistry and Technology. St. Paul, Minnesota, USA: American Association of Cereal Chemists, Inc.,

Oki, T., Masuda, M., Kobayashi, M., Nishiba, Y., Furta, S., Suda, I., and Sato, T. (2002). Polymeric procyanidins as radical-scavenging components in red-hulled rice. Journal Agriculture Food Chemistry, 50, 7524-7529.

Ribeiro, S.M.R., Barbosa, L.C.A., Queiroz, J.H., Knodler, M. and Schieiber, A. (2008). Phenolic compounds and antioxidant capacity of Brazilian mango. Food Chemistry, 110, 620-626.

Shen, Y., Jin L., Xiao, P., Lu, Y. and Bao, J. (2009). Total phenolics, flavonoids, antioxidant capacity in rice grain and their relations to grain color, size and weight. Journal of Cereal Science, 49(1), 106-111. 
Tabart, J., Kevers, C., Pincemail, J., Defraigne, J., and Dommes J. (2009). Comparative antioxidant capacities of phenolic compounds measured by various tests. Food Chemistry, 113(4), 1226-1233.

Tian, S., Nakanura, K. and Kayahara, H. (2004). Analysis of phenolic compounds in white rice brown rice and germinated brown rice. Journal Agriculture Food Chemistry, 52, 4808-4813.

Xia, M., ling, W.H., Kitts, D.D. and Zawistowski, J. (2003). Supplementation of diets with black rice pigment fraction attenuates atherosclerotic plaque formation in apolipoprotein E deficient mice. Journal Nutrition, 133, 744-751.

Yawadio, R., Tanimori, S. and Morita, N. (2007). Identification of phenolic compounds isolated from pigmented rice and their aldose reductase inhibitory activities. Food Chemistry, 101(4), 1616-1625.

Zhang, M.W., Guo, B.J., Zhang, R.F., Chi, J.W., Wei, Z.C., Xu, Z.H., Zhang, Y. and Tang, X.J. (2006). Separation, purification and identification of antioxidant compositions in black rice. Agricultural Science in China, 5(6), 431-440. 